\title{
Relative luminosity in the plus maze upon the exploratory behaviour of female Wistar rats
}

\author{
Efeito da luminosidade relativa em labirinto em cruz sobre o comportamento exploratório \\ de fêmeas Wistar
}

Diana Yae Sakae', Thiago Mamoru Sakae², Marta Aparecida Paschoalini', Moacir Serralvo Faria ${ }^{1}$

\begin{abstract}
Objective: This study evaluated the provision of two configuration of the Elevated Pluz-Maze (EPM) by analizing the exploratory behaviour of female Wistar rats in different phases of the estrous cycle in EPMs with different gradients of luminosity between the open and enclosed $\operatorname{arms}\left(\mathrm{O} / \mathrm{E}_{\Delta L \mathrm{Lx}}\right)$. Methods: Female Wistar rats were treated with Midazolam (MDZ, $\left.1.0 \mathrm{mg} \cdot \mathrm{kg}^{-1}\right)$ and were tested for their exploratory behaviour in either the $\mathrm{EPM} 10 \mathrm{O} / \mathrm{E}_{\Delta L \mathrm{Lx}}$ or EPM $96 \mathrm{O} / \mathrm{E}_{\Delta L \mathrm{Lx}}$. Results: A multiple regression analysis indicated that the $\mathrm{O} / \mathrm{E}_{\Delta L \mathrm{Lx}}$ is negatively associated with the \%Open arm entries and \%Open arm time, suggesting that as $\mathrm{O} / \mathrm{E}_{\Delta \mathrm{Lux}}$ increases, the open arm exploration decreases. The estrous cycle phase did not influence the open-arm exploration in either EPM. MDZ-induced anxiolysis was detected in 96 O/E ${ }_{\Delta L u x}$ EPM in all phases of the EC. Discussion: Results of this study suggest the importance of the $\mathrm{O} / \mathrm{E}_{\Delta L \mathrm{Lx}}$ to establish the arm preference in the EPM, and to preserve the predictive validity of the EPM.
\end{abstract}

Keywords: estrous cycle, female, Wistar rats, anxiety, fear, elevated plus-maze, luminosity.

\section{RESUMO}

Objetivo: Avaliar a provisão de duas configuracōes do Labirinto Elevado em Cruz (LEC) através do comportamento exploratório de ratas Wistar em diferentes fases do ciclo estral (CE) em LEC com diferentes gradientes de luminosidade entre os braços aberto e fechado (A/F $\left.F_{\Delta L u x}\right)$. Método: Ratas Wistar foram tratadas com Midazolam (MDZ, $1.0 \mathrm{mg} \cdot \mathrm{kg}^{-1}$ ) e foram testadas no LEC $10 \mathrm{~A} / \mathrm{F}_{\Delta L \mathrm{Lx}}$ ou LEC $96 \mathrm{~A} / \mathrm{F}_{\Delta L \mathrm{Lx}}$. Resultados: A análise de regressão múltipla indicou que o $A / F_{\Delta L u x}$ está negativamente associado com a \% de entrada no braço aberto e \% de tempo no braço aberto, sugerindo que no aumento do $A / F_{\Delta L u x}$, a exploração do braço aberto diminui. A fase do CE não influenciou a exploração do braço aberto no LEC. A ansiólise induzida pelo MDZ foi demonstrada no 96 LEC A/F ${ }_{\Delta L u x}$ em todas as fases do CE. Discussão: Estes resultados sugerem a importância do $A / F_{\Delta L u x}$ para estabelecer a preferência da exploração do LEC e preservar a validade do LEC.

Palavras-chave: ciclo estral, ratas Wistar, ansiedade, medo, labirinto elevado em cruz, luminosidade.

Animal models have played an important role in furthering our understanding of complex biological basis and mechanisms underlying the pathogenesis of human anxiety. They have also contributed to the provision of preclinical models that enable the discovery and screening of new potential therapeutical drugs ${ }^{1}$. Moreover, animal models of anxiety have been considered as an invaluable approach, since animals display similar autonomic and behavioral reactions during anxiety states ${ }^{2,3,4,5}$.

The present research chose on one of the most popularly used animal models in the study of anxiety-related behaviors ${ }^{6}$ - the Elevated Plus-Maze (EPM). Briefly, the EPM is used as a test of anxiety based on the exploratory behavior of rodents. Its exploratory environment is constituted by four elevated arms, with two opposed open (unprotected spaces) and two other opposed enclosed arms (spaces protected by lateral walls), arranged in a cross-like shape. The open arms are considered regions of the maze endowed with stressful- and fear-inductor properties, because rats exposed to them display increased corticosterone release, as well as fear-related behaviors, when compared to those exposed in the enclosed arms ${ }^{7}$. In this sense, the conflict between the approach and the avoidance of regions with more or less aversive properties underlies the exploratory behavior of animals in the EPM. In fact, this conflict has been considered analogous to human anxiety considering that many anxiety disorders express this insidious avoidance behavior of a feared object or situation ${ }^{8}$. In addition, this conflict is suppressed by anxiolytic drugs used in medical practice, which, in the EPM, selectively increases the open arm exploration?

'Universidade Federal de Santa Catarina, Centro de Ciências Biológicas, Departamento de Ciências Fisiológicas, Florianópolis SC, Brazil;

Universidade do Sul de Santa Catarina, Departamento de Medicina, Tubarao SC, Brazil.

Correspondence: Moacir Serralvo Faria; Universidade Federal de Santa Catarina, Departamento de Ciências Biológicas; Campus Reitor João David Ferreira Lima; 88040-970 Florianópolis SC, Brasil; E-mail: serralvo@ccb.ufsc.br

Conflict of interest: There is no conflict of interest to declare.

Received 25 January 2015; Received in final form 26 February 2015; Accepted 19 March 2015. 
Because of its reach employment, many studies have been devoted to elucidate the methodological variables able to establish the arm preference in the EPM, such as circadian cycle, luminosity incident on the maze, maze height, and animal handling, ${ }^{9,10,11,12}$. However, recently was demonstrated that, for male rats, the difference of illumination between the open and the enclosed arms (i.e, the gradient of luminosity between the open and the enclosed arms; $\mathrm{O} / \mathrm{E}_{\Delta \mathrm{Lux}}$ ), and not the absolute level of luminosity incident on the maze, is the important variable to predict the arm preference in the EPM. Thus, male rats may avoid the open arms because these arms have a higher level of luminosity in relation to the enclosed $\mathrm{arms}^{13}$.

Nevertheless, the influence of the $\mathrm{O} / \mathrm{E}_{\Delta \mathrm{Lux}}$ on the exploratory behavior of female rats in the EPM was not evaluated yet. This point deserves investigation since, from all the studies with EPM, about $25 \%$ have used female rats as experimental subjects. According to the World Health Organization's World Mental Health Survey Initiative ${ }^{14}$, anxiety disorders are the most prevalent of the DSM-IV disorders, with a lifetime prevalence as high as $16.7 \%$. In the case of women, several studies have shown that they present a substantially higher anxiety disorders prevalence than men ${ }^{15,16,17,18}$, which can be up to 3-fold higher in cases of generalized anxiety disorder ${ }^{16}$.

Besides having a low number of studies involving female rats in research with EPM, the data available in the literature reveal conflicting results regarding the influence of estrous cycle on female rats tested in the EPM. Studies have shown that female rats exhibit decreased anxiety when tested in diestrous ${ }^{19}$, proestrous, and estrous ${ }^{20}$ phases of the estrous cycle. In contrast, other studies have failed to indicate significant changes in the exploratory behavior of female rats between the estrous and the diestrous phases of the estrous cycle ${ }^{21}$. Therefore, the literature is quite controversial on the effect of the EC on anxiety-like behaviour in the EPM. Moreover, only one study has evaluated the influence of the absolute level of illumination upon the female rat's behaviour in the EPM ${ }^{22}$.

Finally, taking into consideration the lack of research with female rats in EPM and those conflicting results presented in the literature, the present study aims to evaluate the exploratory behavior of female rats in different phases of the estrous cycle when submitted to EPM with distinct $\mathrm{O} / \mathrm{E}_{\Delta \mathrm{Lux}}$. Also, since the EPM is widly used as a screening test for anxyotitic drugs, the current study also approached if the $\mathrm{O} / \mathrm{E}_{\Delta \mathrm{Lux}}$ alters the detection of an anxyolitic drug by the EPM in female rats in different estrous phases.

\section{METHOD}

\section{Subjects}

A total of 169 female Wistar rats, ranging from 10 to 12 weeks old, and weighting $200 \mathrm{~g}$ to $250 \mathrm{~g}$, were provided by the breeding division of Federal University of Santa Catarina (UFSC). These rats were housed in groups of 5 , having food and water ad libitum, and being exposed to a light/dark cycle of $12 \mathrm{~h}$ (lights on at 06:00) and temperature of $25 \pm 2^{\circ} \mathrm{C}$. Before the experiment, the subjects underwent a habituation period of seven days. The Committee on Animal Research Ethics from UFSC (CEUA - UFSC) provided official permission for the use of animals in our research.

\section{Drug}

Midazolam (MDZ) was dissolved in saline solution $(\mathrm{NaCl} 0.9 \%)$ and administered through i.p. route, at an anxiolytic dose reported in the literature of $1.0 \mathrm{mg} \cdot \mathrm{kg}^{(-1)} 23,24,25$, in a volume of $0.1 \mathrm{ml}$ per $100 \mathrm{~g}$ of body weight.

\section{Apparatus}

The EPM is a wooden apparatus elevated $50 \mathrm{~cm}$ from the floor. It is constituted by four arms of the same size $(50 \mathrm{~cm} \times 10 \mathrm{~cm})$ in a cross-like shape. Two opposed arms are opened and surrounded by only a short $(1.0 \mathrm{~cm})$ glass edge, whereas the other two arms are enclosed by $40 \mathrm{~cm}$ high walls, except for the entrance. For this study, two EPM configurations were used, the enclosed arms walls constituted by translucent glass, and the enclosed arm walls constituted by opaque glass. Also, four 15-W fluorescent lights, the unique source of illumination in the experiment, were arranged in a cross-like format $100 \mathrm{~cm}$ above the maze. These lights, according to the maze configuration, provided different mean level of incident Lux on the open and enclosed arms, as well as, different gradient of luminosity $\left(\mathrm{O} / \mathrm{E}_{\Delta \mathrm{Lux}}\right)$, which is defined as the difference of Lux between the open and the enclosed arms: translucent glass EPM (open arms: 358 Lux, enclosed arms: 348 Lux, $\mathrm{O} / \mathrm{E}_{\Delta \mathrm{Lux}}=10$ ) and opaque glass EPM (open arms: 336 Lux, enclosed arms: $240 \mathrm{Lux}, \mathrm{O} / \mathrm{E}_{\Delta \mathrm{Lux}}=96$ ).

\section{Procedures}

A group of female rats was assigned to receive, through i.p. route, either saline solution $(0.9 \%)$ or $\mathrm{MDZ}\left(1.0 \mathrm{mg} \cdot \mathrm{kg}^{-1}\right)$. Thirty minutes after the drug administration, each group was subdivided into other two groups, which were submitted to either the $10 \mathrm{O} / \mathrm{E}_{\Delta \mathrm{Lux}} \mathrm{EPM}$ or $96 \mathrm{O} / \mathrm{E}_{\Delta \mathrm{Lux}} \mathrm{EPM}$ for 5 minutes. Each animal was placed on the central square of the maze facing an enclosed arm. In order to avoid odoriferous cues between animals, the maze was cleaned with alcohol $20 \%$ (v/v), and then dried with cloths. Any animal that fell off the maze was excluded from the experiment, which occurred in a similar rate in all experimental groups. Each experimental session was recorded by WebCam and subsequently transcribed through Etholog 2.25 software $^{26}$. The standard spatial-temporal variables, such as the number of entries into the open and enclosed arms, were analyzed. Arm entry and arm exit were defined as all four paws into and out of an arm, respectively. The exploratory behavior upon the open arms was expressed as the mean percentage of entries (\%Open arm entries) and the time spent inside the arm (\%Open arm time). Based on the factor analysis of rats in the EPM, the 
\%Open arm entries and \%Open arm time were used as variables negatively correlated with the level of fear/aversion of the open arms, while the Enclosed arm entries were used as a representative variable of animal locomotor activity. All the experiments were carried out between 13:00 and 17:00 h.

Immediately after the EPM exposure, each female had its estrous cycle phase determined by observation of vaginal cytology, as described by Becker et al. ${ }^{27}$. Briefly, an eyedropper was filled with two or three drops of saline solution and then inserted into the vaginal opening of the animal. The fluid was expelled into the vagina and then collected two or three times. This smear was placed onto a slide, and the sample was immediately examined under a light microscope in order to evaluate the vaginal cytology ${ }^{27}$, which are closely correlated with circulating levels of the sex-steroid hormones estrogen and progesterone in the bloodstream ${ }^{28}$.

Three types of cells were identified in the sample: (1) nucleated epithelial cells, (2) leucocytes, and (3) non-nucleated, cornified epithelial cells ${ }^{29}$ (Freeman, 2006). The cycle phases were identified according to the proportion of these type of cells found in the smear ${ }^{30,31}$ (Mandl, 1951; Marcondes, Bianchi et al., 2002).

Metaestrous was identified when the smear contained the same proportion of nucleated epithelial cells and leucocytes, with some disperse non-nucleated, cornified epithelial cells; the diestrous phase was characterized by the predominance of leucocytes and disperse nucleated epithelial cells; proestrous was identified by the the presence of nucleated epithelial cells that are round and were often agregaded; and the estrous phase by the presence of dense layers of non-nucleated, cornified epithelial cells ${ }^{29,30,31}$. Freeman, 2006; Mandl, 1951; Marcondes et al., 2002)

The identification of the estrous cycle phase was carried out after the behavioral test, and vaginal cytology was not monitored before the experimental procedure because animal handling and vaginal-cervical stimulation during sample collection could alter subsequent behavioral responses ${ }^{12}$.

\section{Statistics}

The data were analyzed by Three-Way ANOVA, with $O / A_{\Delta L u x}$ as factor 1, Estrous Cycle as factor 2, and Drug Treatment as factor 3. Three-way ANOVA were followed by Tukey HSD for unequal $\mathrm{N}$, when necessary. In order to estimate whether and how the independent variables relate to the \%Open arm entries,
\%Open arm time, and Enclosed arm entries, a multiple regression analysis was carried out in both experiments. Only p-value less than 0.05 was considered significant (alpha level 0.05).

\section{RESULTS}

At the end of the experiment the ovarian cycle analysis indicated the following experimental groups: the $10 \mathrm{O} / \mathrm{E}_{\Delta \mathrm{Lux}} \mathrm{EPM}$ group treated previously with saline solution: Metaestrous $(n=7)$, Diestrous $(n=19)$, Proestrous $(n=7)$, and Estrous $(\mathrm{n}=12)$; the $96 \mathrm{O} / \mathrm{E}_{\Delta \mathrm{Lux}}$ EPM group treated with saline solution: Metaestrous ( $n=9)$, Diestrous ( $n=21)$, Proestrous ( $n=13)$, and Estrous $(\mathrm{n}=14)$; the $10 \mathrm{O} / \mathrm{E}_{\Delta \mathrm{Lux}} \mathrm{EPM}$ group treated previously with MDZ: Metaestrous ( $\mathrm{n}=7)$, Diestrous $(\mathrm{n}=14)$, Proestrous $(\mathrm{n}=7)$, and Estrous $(\mathrm{n}=8)$. And the $96 \mathrm{O} / \mathrm{E}_{\Delta \mathrm{Lux}}$ EPM group treated previously with MDZ: Metaestrous $(n=10)$, Diestrous $(n=15)$, Proestrous $(n=13)$, and Estrous $(n=11)$.

The results of the three-way ANOVA are exposed in Table 1. ANOVA failed to show any significant main effect for the Estrous cycle factor, as well as any significant interaction between the factors. There was a significant main effect for the Drug treatment and O/E for the variables \%Open arm entries and \%Open arm time, but not for the number of entries into the Enclosed arm (Table 1). Indeed, the number of entries into the enclosed arm was similar in all groups (Figure 1).

Tukey's test indicated that systemic MDZ administration increased the \%Open arm entries and \%Open arm time compared to the saline-treated group (Figure 2). This happened when the animals were tested in $96 \mathrm{O} / \mathrm{E}_{\Delta \mathrm{Lux}} \mathrm{EPM}$, irrespective of the ovarian cycle phase. However, in rats tested in $10 \mathrm{O} / \mathrm{E}_{\Delta \mathrm{Lux}} \mathrm{EPM}$, systemic MDZ administration increased the \%Open arm entries and \%Open arm time only in diestrous and Proestrous phase, but failed to show a statistically significant change in the Metaestrous or Estrous phases.

Table 2 summarizes the results of the multiple linear regression analysis. The data analysis indicated that the independent variable drug treatment was positively associated with the open arm exploration. Thus, as MDZ is administered, both \%Open arm entries and \%Open arm time increase. The independent variable $\mathrm{O} / \mathrm{E}_{\Delta \mathrm{Lux}}$ remained negatively associated with the open arm exploration, that is, as $\mathrm{O} / \mathrm{E}_{\Delta \mathrm{Lux}}$ increases, both \%Open arm

Table 1. Three-way ANOVA results indicating the main effects and between factor interactions.

\begin{tabular}{|c|c|c|c|}
\hline Factors and interactions & \%Open arm entries & \%Open arm time & Enclosed arm entries \\
\hline Drug & $F_{(1,171)}=88.97 ; p<0.05$ & $F_{(1,171)}=120.38 ; p<0.05$ & $F_{(1,171)}=2 \cdot 21 ; N S$ \\
\hline $\mathrm{O} / \mathrm{E}_{\Delta \mathrm{Lux}}$ & $F_{(1,171)}=6.02 ; p<0.05$ & $F_{(1,171)}=7.02 ; p<0.05$ & $F_{(1,171)}=3 \cdot 82 ; N S$ \\
\hline EC & $F_{(3,171)}=0.43 ; N S$ & $F_{(3,171)}=0.77 ; \mathrm{NS}$ & $F_{(3,171)}=0.27 ; \mathrm{NS}$ \\
\hline Drug $\times \mathrm{O} / \mathrm{E}_{\Delta L \mathrm{ux}}$ & $F_{(1,171)}=0.73 ; N S$ & $F_{(1,171)}=1.81 ; \mathrm{NS}$ & $F_{(1,171)}=0.01 ; N S$ \\
\hline Drug $\times$ EC & $F_{(3,171)}=0.41 ; \mathrm{NS}$ & $F_{(3,171)}=2.05 ; \mathrm{NS}$ & $F_{(3,171)}=0.28 ; N S$ \\
\hline $\mathrm{O} / \mathrm{E}_{\Delta \mathrm{Lux}} \times \mathrm{EC}$ & $F_{(3,171)}=0.22 ; \mathrm{NS}$ & $F_{(3,171)}=0.24 ; \mathrm{NS}$ & $F_{(3,171)}=1 \cdot 44 ; N S$ \\
\hline Drug $\times \mathrm{O} / \mathrm{E}_{\Delta L \text { ux }} \times \mathrm{EC}$ & $F_{(3,171)}=0.52 ; \mathrm{NS}$ & $F_{(3,171)}=0.21 ; N S$ & $F_{(3.171)}=0.36 ; \mathrm{NS}$ \\
\hline
\end{tabular}

Female Wistar rats in different phases of the estrous cycle (EC) were treated with either saline (0.9\%) or Midazolam (1.0 mg.kg-1) through i.p. route and submitted to elevated plus maze with different level of illumination between the open and enclosed arms (O/E $\left.\mathrm{E}_{\text {u.ux }}\right)$. NS indicates not significant. 


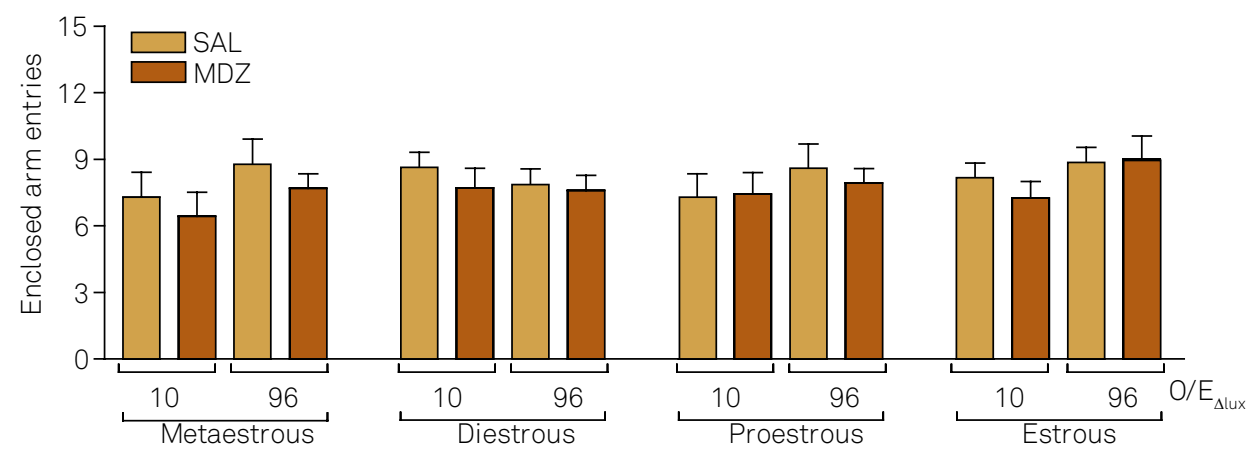

Female Wistar rats in different phases of the estrous cycle were treated with either saline (SAL, 0.9\%) ou Midazolam (MDZ; $1.0 \mathrm{mg} . \mathrm{kg}^{-1}$ ) through i.p. route and submitted to elevated plus maze with different level of illumination between the open and enclosed arms (O/E $\left.{ }_{\Delta L x}\right)$. Data are represented as the mean \pm S.E.M. No significant differences between the groups were observed (Three-Way ANOVA followed by Tukey's for unequal $n$ ).

Figure 1. Number of entries into the enclosed arms in female Wistar rats treated systemically with either saline or MDZ.
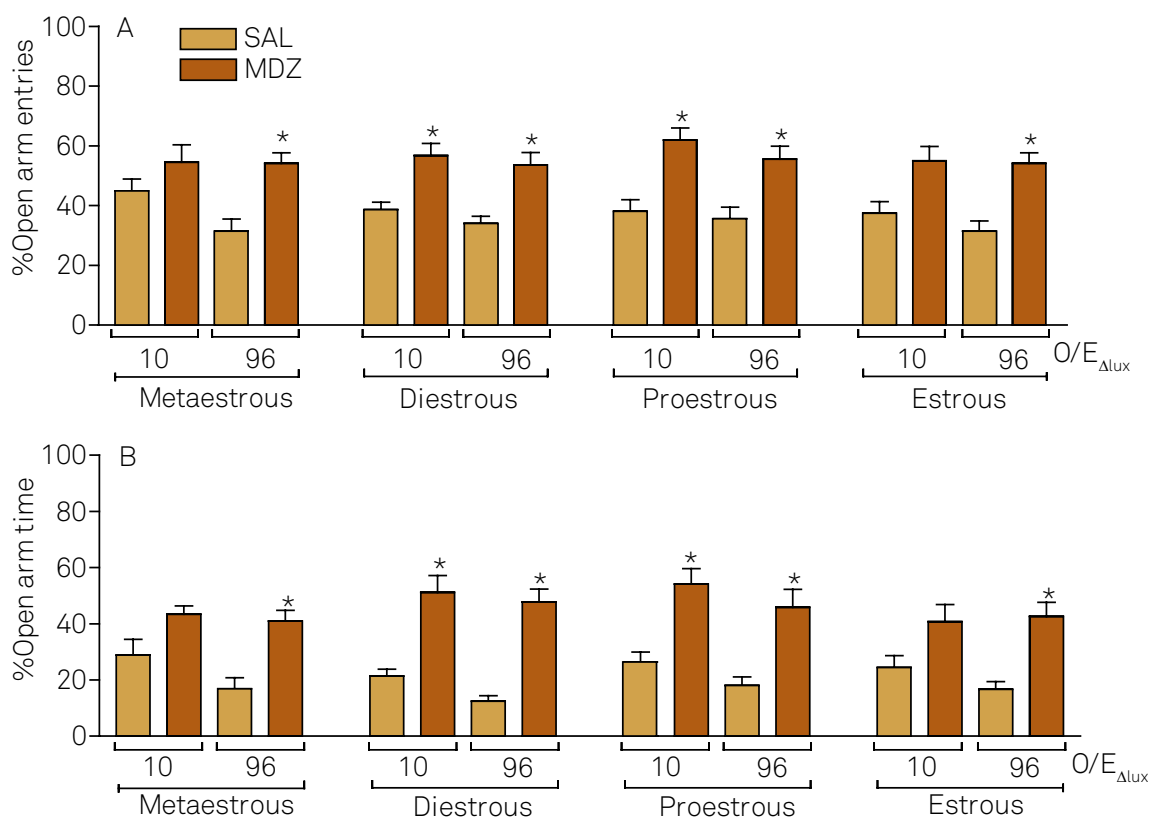

Female Wistar rats in different phases of the estrous cycle were treated with either saline (SAL, 0.9\%) ou Midazolam (MDZ; 1.0 mg.kg-1) through i.p. route and submitted to elevated plus maze with different level of illumination between the open and enclosed arms $\left(0 / \mathrm{E}_{\Delta L \mathrm{ux}}\right)$. The $\% 0$ pen arm entries is depicted in panel A while de \%Open arm time is depicted in panel B. Data are represented as the mean \pm S.E.M. * $p<0.05$ in relation to the group treated with saline (Three-Way ANOVA followed by Tukey's for unequal $n$ ).

Figure 2. Impaired detection of the anxiolytic-like effect induced by MDZ in an elevated plus maze with low gradient of luminosity between the open and enclosed arms.

entries and \%Open arm time decrease. Regarding the independent variable Estrous cycle, there was no association with both \%Open arm entries and \%Open arm time. Neither of the independent variables was associated with the Enclosed arm entries.

\section{DISCUSSION}

Research carried out with rats in the EPM have shown that rats exhibit preference by the enclosed arms $^{7}$ because the open arms are regions endowed with stressful- and fear-inductor properties. In fact, rats exposed to the open arms display increased corticosterone release, as well as fear-related behaviors, when compared to those exposed in the enclosed arms ${ }^{7}$. It was originally proposed that a fear induced by the rat's inability to carry out open arms exploration through the vibrissae is what underlies the establishment of arm preference in the $\mathrm{EPM}^{32}$.

The relative luminosity between open and enclosed arms, and not the absolute level of luminosity on the maze, was recently demonstrated to be another determinant variable for the establishment of arm preference in the $\mathrm{EPM}^{13}$. As the open arms are more illuminated than the enclosed arms, the ability of the animal to discriminate areas in the EPM with more or less luminosity may drive the maze exploration toward the areas with low fear-inductor properties, thus establishing the enclosed arm preference. Therefore, in addition to vibrissae system, another suggestion is that the visual system may underlie the arm preference of rodents during EPM exploration.

The behavioural baseline of male rats tested in the EPM has shown to be dependent on the $\mathrm{O} / \mathrm{E}_{\Delta \mathrm{Lux}}$, an indicator of the 
Table 2. Multiple regression analysis results indicating the Beta values relative to the associations between the independent and the dependent variables.

\begin{tabular}{|c|c|c|c|c|c|c|}
\hline \multirow{3}{*}{ Independent variables } & \multicolumn{6}{|c|}{ Dependent variables } \\
\hline & \multicolumn{2}{|c|}{ \%Open arm entries } & \multicolumn{2}{|c|}{ \%Open arm time } & \multicolumn{2}{|c|}{ Enclosed entries } \\
\hline & Beta & $\mathrm{p}$-value & Beta & $\mathrm{p}$-value & Beta & $p$-value \\
\hline Drug treatment & 0.602 & $<0.05$ & 0.668 & $<0.05$ & -0.113 & NS \\
\hline $\mathrm{O} / \mathrm{E}_{\Delta L \mathrm{ux}}$ & -0.145 & $<0.05$ & -0.158 & $<0.05$ & 0.100 & NS \\
\hline Estrous cycle & -0.028 & NS & -0.041 & NS & -0.015 & NS \\
\hline
\end{tabular}

Female Wistar rats in different phases of the estrous cycle were treated with either saline (0.9\%) or Midazolam (1.0 mg.kg-1) by i.p. route and submitted to elevated plus maze with different level of illumination between the open and enclosed arms (O/E $\left.{ }_{\text {ux }}\right)$. R value 0.618 (\%Open arm entries); R value 0.686 (\%Open arm time); R value 0.151 (Enclosed entries); NS indicates not significant.

relative luminosity between the arms of the maze. This is so, because the animals have displayed a low level of fear and a decrease in open arms avoidance under smaller $\mathrm{O} / \mathrm{E}_{\Delta L \mathrm{ux},}$, and an increase in their level of fear and open arms avoidance under higher $\mathrm{O} / \mathrm{E}_{\Delta \mathrm{Lux}}{ }^{13}$. Other researchers have also shown that mice are similarly able to discriminate enclosed arms with different levels of brightness in a modified $\mathrm{EPM}^{31}$, thus aiming for the importance of the level of luminosity to drive the exploratory behaviour of the animal in the EPM.

In contrast with research conducted with male rats ${ }^{13}$, the data from multiple linear regressions revealed a significant negative association between the independent variable $\mathrm{O} / \mathrm{E}_{\Delta \mathrm{Lux}}$ and the dependent variables representatives of the open arm exploration, thus indicating that as $\mathrm{O} / \mathrm{E}_{\Delta \mathrm{Lux}}$ increase, both \%Open arm entries and \%Open arm time decrease. Therefore, the present study suggests that $\mathrm{O} / \mathrm{E}_{\Delta \mathrm{Lux}}$ is also important for the establishment of arm preference in the case of female Wistar rats.

Regarding the locomotor activity of the animals, ANOVA failed to indicate a significant main effect for the number of entries into the enclosed arms in relation to the $\mathrm{O} / \mathrm{E}_{\Delta \mathrm{Lux}}$ factor. As the multiple regression analysis also did not show a significant association between the $\mathrm{O} / \mathrm{E}_{\Delta \mathrm{Lux}}$ and Enclosed arm entries variable, the present study proposes that the locomotor activity of female Wistar rats, in accordance with male, is not altered by variations of the relative luminosity between the open and enclosed arms of the EPM.

The present study also demonstrated that the $\mathrm{O} / \mathrm{E}_{\Delta L u x}$ is an important methodological variable to be controlled, since it has the ability to alter the predict validity of the EPM in recognizing anxiolytic drugs clinically effective. Accordingly, from the female rats that received the MDZ systemically in the Metaestrous and Estrous phases of the ovarian cycle, only the $96 \mathrm{O} / \mathrm{E}_{\Delta L \mathrm{ux}} \mathrm{EPM}$ was able to detect the antiaversive and anxiolytic properties of the drug when evaluated through either \%Open arm entries or \%Open arm time. However, the same dose of MDZ failed to increase the open arm exploration when females were tested in the $10 \mathrm{O} / \mathrm{E}_{\Delta \mathrm{Lux}} \mathrm{EPM}$ during these same phases of the estrous cycle.

This may have occurred due to changes in the baseline bahaviour of the animals treated with saline, which was higher in female tested in the $10 \mathrm{O} / \mathrm{E}_{\Delta \mathrm{Lux}}$ than in those tested in the $96 \mathrm{O} / \mathrm{E}_{\Delta \mathrm{Lux}}$. If a full anxiolytic effect in the EPM is characterized by absence of arm preference (around 50\% in the \%Open arm entries and \%Open arm time), we believe that as baseline increases, the probability of the EPM to detect anxiolytic-like drugs decreases, and this may happen due to a ceiling effect. This fact suggests that special attention should be given either to the material of manufacture of the enclosed arm walls or to the maze illumination source, or yet, to both, in order to reach a level of $\mathrm{O} / \mathrm{E}_{\Delta \mathrm{Lux}}$ compatible with an arm preference in intermediate values. Consequently, these suggestions will account to avoid false positive (effect floor) and negative (effect ceiling) results, and improve the sensitivity of the model to screen putative anxiolytic- and anxiogenic-like drugs.

Regarding the influence of the estrous cycle upon the behaviour of female rats in the EPM, the present study indicated that, irrespective of the phase of the Ovarian cycle, the arm preference was not changed. In fact, there was neither a significant ANOVA main effect for the Estrous cycle variable, nor a significant association between Estrous cycle and the variables representative of open arm exploration. The same is true for the number of entries into the enclosed arms. Therefore, the hormonal fluctuations underlying the ovarian cycle did not changed the animals behaviour in the EPM. This result is in accordance with previous studies on the literature, which indicate that the behaviour of female rats remain unchanged regardless of the estrous cycle phase of the animals ${ }^{21}$. However, previous research have also shown that the level of open arm exploration is increased during Proestrous ${ }^{19,20,22}$, Estrous ${ }^{20,22}$, and Metaestrous ${ }^{22}$. Comparing these results with the present study is difficult, because some of these cases presented in the literature provided the absolute (not the relative) level of illumination; and in some other cases the level of illumination was not even provided.

Some important conclusions regarding the exploratory behavior of female Wistar rats in different phases of the Estrous cycle emerge from the present study. The first one is that the $\mathrm{O} / \mathrm{E}_{\Delta \mathrm{Lux}}$ is an important methodological variable for the establishment of arm preference in the EPM. Another conclusion is that it becomes important to establish a suitable level of illumination between the open and enclosed arms of the maze in order to avoid false positive results when screening new putative anxiolytic-like drugs, since as $\mathrm{O} / \mathrm{E}_{\Delta \mathrm{Lux}}$ decrease, the predict validity of the EPM may be impaired. And finally, the exploratory behaviour of female Wistar rats in the EPM remains unchanged irrespective of the estrous cycle phase. 
1. Leonardo ED, Hen R. Anxiety as a developmental disorder. Neuropsychopharmacology. 2008;33(1):134-40. http://dx.doi.org/10.1038/sj.npp.1301569

2. Blanchard DC, Griebel G, Blanchard RJ. Mouse defensive behaviors: pharmacological and behavioral assays for anxiety and panic. Neurosci Biobehav Rev. 2001;253):205-18. http://dx.doi.org/10.1016/S0149-7634(01)00009-4

3. Borsini F, Podhorna J, Marazziti D. Do animal models of anxiety predict anxiolytic-like effects of antidepressants? Psychopharmacology (Berl). 2002;163(2):121-41. http://dx.doi.org/10.1007/s00213-002-1155-6

4. Leonardo ED, Hen R. Genetics of affective and anxiety disorders. Annu Rev Psychol. 2006;57(1):117-37. http://dx.doi.org/10.1146/annurev.psych.57.102904.190118

5. Hohoff C. Anxiety in mice and men: a comparison. J Neural Transm. 2009;116(6):679-87. http://dx.doi.org/10.1007/s00702-009-0215-z

6. Ramos A. Animal models of anxiety: do I need multiple tests? Trends Pharmacol Sci. 2008;29(10):493-8. http://dx.doi.org/10.1016/j.tips.2008.07.005

7. Pellow S, Chopin P, File SE, Briley M. Validation of open:closed arm entries in an elevated plus-maze as a measure of anxiety in the rat. J Neurosci Methods. 1985;14(3):149-67. http://dx.doi.org/10.1016/0165-0270(85)90031-7

8. Sato T. The internal conflict model: a theoretical framework for integration. Humanistic Psychol. 2005;33(1):33-44. http://dx.doi. org/10.1207/s15473333thp3301_4

9. Jones N, King SM. Influence of circadian phase and test illumination on pre-clinical models of anxiety. Physiol Behav. 2001;72(1-2):99-106. http://dx.doi.org/10.1016/S0031-9384(00)00388-7

10. Becker A, Grecksch G. Illumination has no effect on rats' behavior in the elevated plus-maze. Physiol Behav. 1996;59(6):1175-7. http://dx.doi.org/10.1016/0031-9384(95)02224-4

11. Garcia AM, Cardenas FP, Morato S. Effect of different illumination levels on rat behavior in the elevated plus-maze. Physiol Behav. 2005;85(3):265-70. http://dx.doi.org/10.1016/j.physbeh.2005.04.007

12. Andrews N, File SE. Handling history of rats modifies behavioural effects of drugs in the elevated plus-maze test of anxiety. Eur J Pharmacol. 1993;235(1):109-12. http://dx.doi.org/10.1016/0014-2999(93)90827-5

13. Pereira LO, da Cunha IC, Neto JM, Paschoalini MA, Faria MS. The gradient of luminosity between open/enclosed arms, and not the absolute level of Lux, predicts the behaviour of rats in the plus maze. Behav Brain Res. 2005;159(1):55-61. http://dx.doi.org/10.1016/j.bbr.2004.10.002

14. Kessler RC, Angermeyer M, Anthony JC, DE Graaf R, Demyttenaere K, Gasquet I et al. Lifetime prevalence and age-of-onset distributions of mental disorders in the World Health Organization's World Mental Health Survey Initiative. World Psychiatry. 2007;6(3):168-76.

15. Afifi M. Gender differences in mental health. Singapore Med J. 2007;48(5):385-91

16. Bekker MH, Mens-Verhulst J. Anxiety disorders: sex differences in prevalence, degree, and background, but gender-neutral treatment. Gend Med. 2007;4 Suppl 2:S178-93.

17. Simonds VM, Whiffen VE. Are gender differences in depression explained by gender differences in co-morbid anxiety? J Affect Disord. 2003;77(3):197-202. http://dx.doi.org/10.1016/S0165-0327(02)00113-1

18. Wittchen HU, Zhao S, Kessler RC, Eaton WW. DSM-III-R generalized anxiety disorder in the National Comorbidity Survey. Arch Gen Psychiatry. 1994;51(5):355-64. http://dx.doi.org/10.1001/archpsyc.1994.03950050015002
19. Marcondes FK, Miguel KJ, Melo LL, Spadari-Bratfisch RC. Estrous cycle influences the response of female rats in the elevated plus-maze test. Physiol Behav. 2001;74(4):435-40. http://dx.doi.org/10.1016/S0031-9384(01)00593-5

20. Díaz-Véliz G, Alarcón T, Espinoza C, Dussaubat N, Mora S. Ketanserin and anxiety levels: influence of gender, estrous cycle, ovariectomy and ovarian hormones in female rats. Pharmacol Biochem Behav. 1997;58(3):637-42. http://dx.doi.org/10.1016/S0091-3057(97)90004-6

21. Nomikos GG, Spyraki C. Influence of oestrogen on spontaneous and diazepam-induced exploration of rats in an elevated plus maze. Neuropharmacology. 1988;27(7):691-6. http://dx.doi.org/10.1016/0028-3908(88)90077-9

22. Mora S, Dussaubat N, Díaz-Véliz G. Effects of the estrous cycle and ovarian hormones on behavioral indices of anxiety in female rats. Psychoneuroendocrinology. 1996;21(7):609-20. http://dx.doi.org/10.1016/S0306-4530(96)00015-7

23. Albrechet-Souza L, Oliveira AR, De Luca MC, Tomazini FM, Santos NR, Brandão ML. A comparative study with two types of elevated plus-maze (transparent vs. opaque walls) on the anxiolytic effects of midazolam, one-trial tolerance and fear-induced analgesia. Prog Neuropsychopharmacol Biol Psychiatry. 2005;29(4):571-9. http://dx.doi.org/10.1016/j.pnpbp.2005.01.010

24. Rosa VP, Vandresen N, Calixto AV, Kovaleski DF, Faria MS. Temporal analysis of the rat's behavior in the plus-maze: effect of midazolam. Pharmacol Biochem Behav. 2000;67(1):177-82. http://dx.doi.org/10.1016/S0091-3057(00)00316-6

25. Godinho MAA, Meneghini L, Lucinda AM, Borges FR, Sakae DY, Marino $J$ et al. An approach to evaluate the ability of rats to discriminate different levels of illumination in the plus maze test: effects of scopolamine. Behav Brain Res. 2007;180(1):86-94. http://dx.doi.org/10.1016/j.bbr.2007.02.024

26. Ottoni EB. EthoLog 2.2: a tool for the transcription and timing of behavior observation sessions. Behav Res Methods Instrum Comput. 2000;32(3):446-9. http://dx.doi.org/10.3758/BF03200814

27. Becker JB, Arnold AP, Berkley KJ, Blaustein JD, Eckel LA, Hampson E et al. Strategies and methods for research on sex differences in brain and behavior. Endocrinology. 2005;146(4):1650-73. http://dx.doi.org/10.1210/en.2004-1142

28. Frick KM, Burlingame LA, Arters JA, Berger-Sweeney J. Reference memory, anxiety and estrous cyclicity in C57BL/6NIA mice are affected by age and sex. Neuroscience. 2000;95(1):293-307. http://dx.doi.org/10.1016/S0306-4522(99)00418-2

29. Freeman ME. Neuroendocrine control of the ovarian cycle of the rat. In: Jimmy DN, Tony MP, Donald WP, John RGC, David MDK, Joanne SR et al., eds. Knobil and Neill's physiology of reproduction. 3rd ed. St Louis: Academic Press; 2006. p. 2327-88.

30. Mandl, A.M. The phases of the oestrous cycle in the adult white rat.J Exp Biol. 1951;28:576-84.

31. Marcondes FK, Bianchi FJ, Tanno AP. Determination of the estrous cycle phases of rats: some helpful considerations. Braz J Biol. 2002;62(4):609-14. http://dx.doi.org/10.1590/S1519-69842002000400008

32. Treit D, Menard J, Royan C. Anxiogenic stimuli in the elevated plus-maze. Pharmacol Biochem Behav. 1993;44(2):463-9. http://dx.doi.org/10.1016/0091-3057(93)90492-C

33. Dere E, Topic B, Silva MAS, Srejic M, Frisch C, Buddenberg T et al. The graded anxiety test: a novel test of murine unconditioned anxiety based on the principles of the elevated plus-maze and light-dark test. J Neurosci Methods. 2002;122(1):65-73. http://dx.doi.org/10.1016/S0165-0270(02)00274-1 